ARTICLE

\title{
Development of highly efficient platinum catalysts for hydroalkoxylation and hydroamination of unactivated alkenes
}

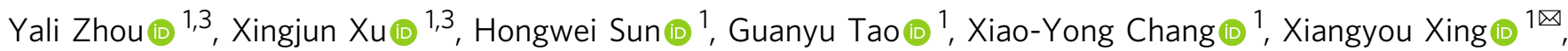
Bo Chen (i) ${ }^{2 \otimes} \&$ Chen Xu (i) ${ }^{1 凶}$

Hydrofunctionalization, the direct addition of an $\mathrm{X}-\mathrm{H}$ (e.g., $\mathrm{X}=\mathrm{O}, \mathrm{N}$ ) bond across an alkene, is a desirable strategy to make heterocycles that are important structural components of naturally occurring molecules. Described here is the design and discovery of "donor-acceptor"-type platinum catalysts that are highly effective in both hydroalkoxylation and hydroamination of unactivated alkenes over a broad range of substrates under mild conditions. A number of alkene substitution patterns are accommodated, including tri-substituted, 1,1-disubstituted, (E)-disubstituted, (Z)-disubstituted and even mono-substituted double bonds. Detailed mechanistic investigations suggest a plausible pathway that includes an unexpected dissociation/re-association of the electron-deficient ligand to form an alkenebound "donor-acceptor"-type intermediate. These mechanistic studies help understand the origins of the high reactivity exhibited by the catalytic system, and provide a foundation for the rational design of chiral catalysts towards asymmetric hydrofunctionalization reactions.

\footnotetext{
${ }^{1}$ Shenzhen Grubbs Institute and Department of Chemistry, Guangdong Provincial Key Laboratory of Catalysis, Southern University of Science and Technology, Shenzhen, Guangdong, China. ${ }^{2}$ Academy for Advanced Interdisciplinary Studies, Southern University of Science and Technology, Shenzhen, Guangdong, China. ${ }^{3}$ These authors contributed equally: Yali Zhou, XingjunXu. ${ }^{凶}$ email: xingxy@sustech.edu.cn; chenb@sustech.edu.cn; xuc@sustech.edu.cn
} 
A liphatic or aromatic ethers and amines are often significant structural components of biologically active natural products ${ }^{1,2}$. Of the methods to generate these prevalent motifs, the most straightforward and atom-economical route would involve the direct addition of an $\mathrm{O}-\mathrm{H}$ or an $\mathrm{N}-\mathrm{H}$ bond across an alkene, commonly referred to as hydroalkoxylation and hydroamination, respectively. In the past decade, there have been a growing number of reports for catalysts that can facilitate hydroalkoxylation ${ }^{3-14}$ and hydroamination ${ }^{15-29}$. To the best of our knowledge, the most frequently used methods are metal-catalyzed conditions, which have been primarily enabled by the activation of either the nucleophile $(\mathrm{OH}$ or $\mathrm{NH}$ group $)^{6,8,9,14,16}$ or the electrophile $(\mathrm{C}=\mathrm{C} \text { bond })^{4,5,19,20,23}$ with varying degrees of efficiency (Fig. 1a). Of the metals that are able to catalyze hydroalkoxylation and hydroamination, platinum catalysts attracted considerable attention for its unique Lewis acidity towards $\mathrm{C}=\mathrm{C}$ double bonds $\mathrm{s}^{30,31}$. Platinum-based complexes that can selectively activate simple $\mathrm{C}=\mathrm{C}$ double bonds could fall into the following three categories (Fig. 1b) ${ }^{32}$. (1) Anionic systems, such as the famous Zeise's salt (K
$\left.\left[\mathrm{PtCl}_{3}\left(\mathrm{C}_{2} \mathrm{H}_{4}\right)\right] \cdot \mathrm{H}_{2} \mathrm{O}\right)$ and Chojnacki's salt $\left(\mathrm{K}\left[\mathrm{PtBr}_{3}\left(\mathrm{C}_{2} \mathrm{H}_{4}\right)\right]\right)$. (2) Neutral systems ${ }^{33,34}$, such as $\left[\mathrm{PtCl}_{2}\left(\mathrm{C}_{2} \mathrm{H}_{4}\right)_{2}\right]_{2}$ that have been introduced by Widenhoefer ${ }^{4,19,33,34}$. (3) Cationic systems, with diamine ${ }^{35-38}$, bisphosphine ${ }^{39,40}$, carbene $e^{41-43}$ or pincer ligands ${ }^{4-46}$; in particular, Gagné discovered a series of elegant cationic $\mathrm{Pt}(\mathrm{II})$ complexes, such as (PPP) $\mathrm{Pt}^{2+}$ and (PP) $\mathrm{PPt}^{2+}$, which efficiently inhibit $\beta-\mathrm{H}$ elimination as a competing decomposition pathway ${ }^{31,40,46}$. Among the three activation modes, coordination to the cationic Pt derivatives renders the multiple bonds more electrophilic and thus susceptible to nucleophilic attack ${ }^{47,48}$.

Recently, Grubbs described the design and synthesis of novel "donor-acceptor"-type platinum catalysts by introducing electron-rich bisphosphine and electron-deficient dimethylphosphine oxide on the platinum center, and these catalysts have been demonstrated to be highly effective in the hydration of nitriles and cyanohydrins at ambient temperature ${ }^{49}$. We envisioned that this catalyst design concept may be suitable for the cationic, electrophilic activation of olefins: introducing both electron-rich "donor" ligand and electron-deficient "acceptor"

(a) Activation modes for metal catalyzed hydroalkoxylation and hydroamination.

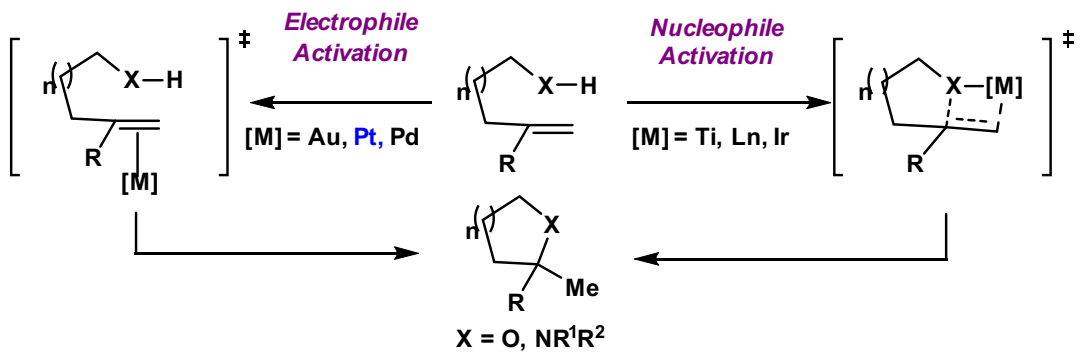

(b) Activatin of alkenes by Pt-based catalytic systems

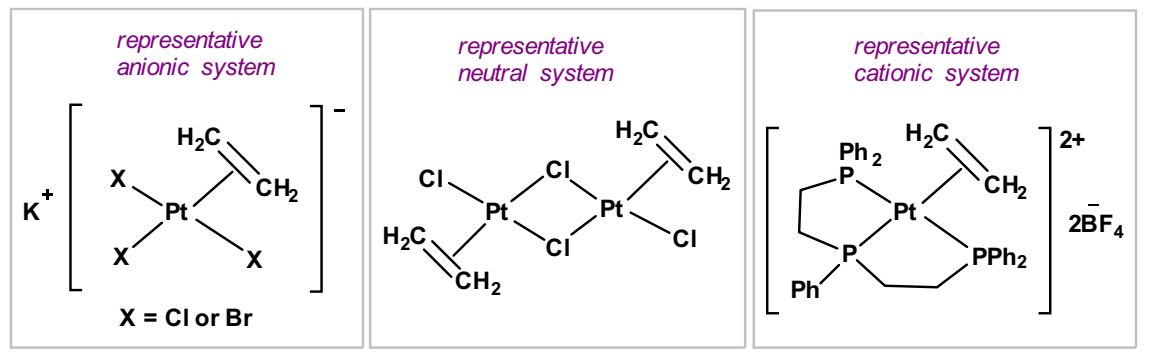

(c) This work: designed "donor-acceptor " catalysts and their high activities in hydroalkoxylation and hydroamination

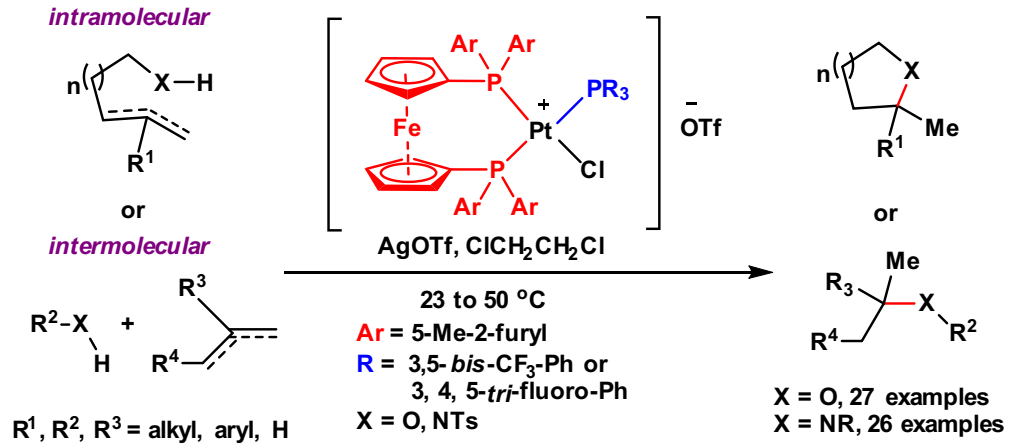

Fig. 1 Pt-catalyzed hydroalkoxylation and hydroamination of unactivated alkenes. a Activation modes for metal-catalyzed hydroalkoxylation and hydroamination. b Activation of alkenes by Pt-based catalytic systems. c This work: designed "donor-acceptor" catalysts and their high activities in hydroalkoxylation and hydroamination. 


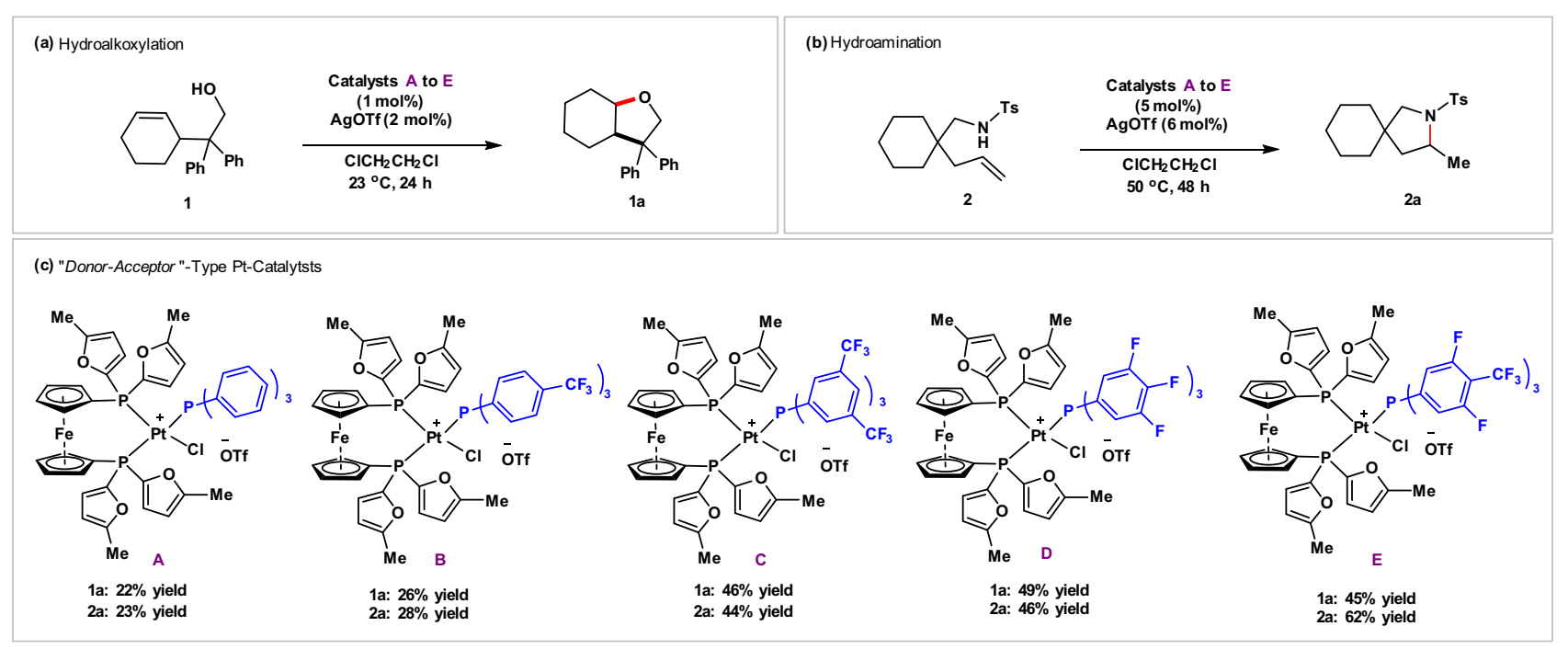

Fig. 2 Development of "donor-acceptor" type Pt catalysts for hydroalkoxylation and hydroamination. a Hydroalkoxylation. b Hydroamination. c Screening of "donor-acceptor"-type Pt catalysts for hydroalkoxylation and hydroamination.

ligand to the Pt center would make a soft and stable cationic system $^{50,51}$, thus leading to a more effective activation of soft Lewis bases, such as $\mathrm{C}-\mathrm{C}$ multiple bonds.

Herein, we disclose readily accessible "donor-acceptor"-type platinum catalysts that are highly active in both hydroalkoxylation and hydroamination, along with mechanistic studies that reveal the origins of the high reactivity of the catalytic system. The hydroalkoxylation and hydroamination reactions catalyzed by the Pt-complexes typically proceed at mild temperatures (23$50^{\circ} \mathrm{C}$ ), and encompass a remarkably broad substrate scope, including alkenes with various substitution patterns (Fig. 1c). Chiral platinum catalysts bearing $(R)$-BINAP or $(R)$-Difluorphos and an electron-deficient monodentate ligand with hydrogenbonding site allows the asymmetric hydroalkoxylation and hydroamination with enantioselectivities, supporting that a more complex metal catalyst than triflic acid is involved ${ }^{52-55}$. Mechanistic data reveal an unusual dissociation/re-association of the electron-deficient monophosphine, and that a polarizable alkene-bound "donor-acceptor"-type Pt-intermediate could be formed, thus facilitating activation of simple alkenes.

\section{Results}

Screening of the optimal catalysts. In Grubbs' previous studies on the hydration of nitriles and cyanohydrins, more electron-rich groups in the "donor" moiety were discovered to increase the activity of the catalysts ${ }^{49}$. Therefore, we take the electron-rich $1.1^{\prime}$ [bis(5-methyl-2-furanyl)phosphine]ferrocene "donor" ligand and modulate the electronic nature of the monodentate "acceptor" ligands. As shown in Fig. 2, five Pt catalysts A-E were synthesized via the reaction of $1.1^{\prime}$-[bis(5-methyl-2-furanyl)phosphine]ferrocene platinum dichloride $\left(\mathrm{dmfpfPtCl} \mathrm{Pl}_{2}\right)$ with the corresponding monodentate phosphine ligands (in blue) in the presence of silver triflate, respectively (Please see the details in Supplementary Information). Then the activity of the synthesized platinum catalysts was evaluated by performing hydroalkoxylation of $\mathbf{1}$ and hydroamination of 2 (Fig. 2). The results show that catalyst $\mathbf{A}$, with triphenylphosphine as the monodentate ligand, has the worst reactivity for both hydroalkoxylation of $\mathbf{1}$ and hydroamination of 2. Catalyst $\mathbf{B}$ that bears electron-deficient monodentate tris(4(trifluoromethyl)phenyl)phosphine slightly improved the reactivity for both hydroalkoxylation and hydroamination. Catalyst $\mathbf{C}$ harboring the more electron-deficient monodentate tris(3,5-bis (trifluoromethyl)phenyl)phosphine displays noticeably increased catalytic activity, providing hydroalkoxylation product $\mathbf{1 a}$ and hydroamination product $\mathbf{2 a}$ in $46 \%$ and $44 \%$ yields, respectively. The observation that more electron-deficient tri-aryl phosphine ligand in the "acceptor" moiety resulted in higher catalytic activity as demonstrated by the improved performance of catalysts $\mathbf{A}, \mathbf{B}$, and C supports Grubbs' "donor-acceptor" catalyst design ${ }^{49}$. Catalysts $\mathbf{D}$ and $\mathbf{E}$ bearing other two different electron-deficient monodentate ligands, tris(3,4,5-trifluorophenyl)phosphine and tris(3,5-difluoro-4-(trifluoromethyl)phenyl)phosphine, also show good reactivity for both hydroalkoxylation and hydroamination, and have their own advantages for different substrates. The trend that more electron-rich group in the "donor" part ${ }^{49}$ and/or the more electron-deficient group in the "acceptor" part increased the activity of the Pt catalysts could be explained: the cationic $\mathrm{Pt}(\mathrm{II})$ was stabilized by the strong $\sigma$ donating from the electron-rich bidentate ligand, while the electron-deficient monodentate ligand which acts as weak $\sigma$ donor but strong $\pi$ acceptor makes the $\operatorname{Pt}(\mathrm{II})$ center more electrophilic toward multiple bonds ${ }^{56}$.

Scope for hydroalkoxylation. we next investigated the scope of intramolecular hydroalkoxylation with catalyst $\mathbf{C}$, which contains the commercially available and inexpensive tris(3,5-bis(trifluoromethyl)phenyl)phosphine as the monodentate ligand (Fig. 3). All the reactions were conducted under mild conditions (either at 23 or $50{ }^{\circ} \mathrm{C}$ ). The catalytic protocol displays excellent generality with Markovnikov regioselectivity, and is notably applicable to the synthesis of sterically hindered ethers with fused-, bridged-, and spiro-ring systems (Fig. 3, entries 5; 15;2, 3, $6,9,10,13$, and 20). Various hydroxyl groups, such as primary, secondary, tertiary alcohols and phenols serve as good nucleophiles. Different olefins with various substitution patterns including trisubstituted (Fig. 3, entries 1-6), 1,1-disubstituted (Fig. 3, entries 7-15), 1,2-disubstituted (both cis and trans) (Fig. 3, entries 16-18), and even mono-substituted (Fig. 3, entries 19 and 20) double bonds work well in this reaction. Good to excellent yields were obtained in all cases reported.

Expanding our investigation to intermolecular hydroalkoxylation, we discovered that catalyst $\mathbf{D}$ was the optimal catalyst whereas $\mathbf{C}$ gave slightly reduced yields over a range of different substrates (Fig. 4). Higher catalyst loadings ( $5 \mathrm{~mol} \%$ ) and slightly elevated temperatures are required for optimal conversion of the intermolecular reactions reported here. Alkenes with ring strain, such as norbornene (23), comphene (24), and four-membered 


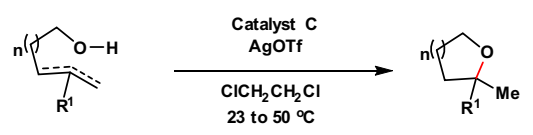

\begin{tabular}{|c|c|c|c|c|c|c|c|}
\hline Entry & Alkenyl alcohol & Heterocycle & Yield (\%) & Entry & Alkenyl alcohol & Heterocycle & Yield (\%) \\
\hline 1 & & 3a & 90 & 11 & 13 & 13a & 86 \\
\hline 2 & & $4 a$ & 80 & 12 & 14 & $14 a$ & 70 \\
\hline 3 & 5 & $5 a$ & 85 & 13 & 15 & $15 a$ & 60 \\
\hline 4 & 6 & 6a & 95 & 14 & 16 & $16 a$ & 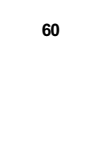 \\
\hline 5 & $( \pm)-7$ & (士)-7a & 80 & $15^{\mathrm{a}}$ & 17 & $17 a$ & 50 \\
\hline $6^{\mathrm{a}}$ & 8 & $8 a$ & $92^{\mathrm{b}}$ & $16^{\mathrm{a}}$ & 18 & 18a & 80 \\
\hline 7 & & 9a & 95 & $17^{\mathrm{a}}$ & & 107 & 85 \\
\hline 8 & 10 & 10a & 95 & $18^{\mathrm{a}}$ & 20 & 20a & 67 \\
\hline 9 & 11 & 11a & 92 & $19^{\mathrm{a}}$ & & 21a & 80 \\
\hline 10 & 12 & $12 \mathrm{a}$ & 87 & $20^{\mathrm{a}}$ & 22 & 22a & 70 \\
\hline
\end{tabular}

Fig. 3 Substrate scope for intramolecular hydroalkoxylation. General conditions: Catalyst $\mathbf{C}(1 \mathrm{~mol} \%), \mathrm{AgOTf}\left(2 \mathrm{~mol}^{\circ}\right), \mathrm{ClCH}_{2} \mathrm{CH}_{2} \mathrm{Cl}, 23^{\circ} \mathrm{C}, 24 \mathrm{~h}$. Yields of isolated products are given. a Catalyst $\mathbf{C}(2 \mathrm{~mol} \%), \mathrm{AgOTf}(4 \mathrm{~mol} \%), \mathrm{ClCH}_{2} \mathrm{CH}_{2} \mathrm{Cl}, 50{ }^{\circ} \mathrm{C}, 48 \mathrm{~h}$. Yields of isolated products are given. ${ }^{b} \mathrm{Determined} \mathrm{by}{ }^{1} \mathrm{H}$ NMR analysis using 4,4'-di-tert-butyl-1,1'-biphenyl as an internal standard.

carbocycles (25) all productively undergo intermolecular hydroalkoxylation reactions with alcohols. Acyclic alkenes, such as $\mathbf{2 6}$ and 27 that are less reactive substrates than their cyclic counterparts were coupled with alcohols in moderate yields. These reactions generally stalled at 30-70\% conversions depending on the nature of the nucleophile used; longer reaction times or higher catalyst loadings do not help to convert the reactions further. Intermolecular hydroalkoxylation of norbornene (23) with para-substituted phenols was also investigated. Phenols have a potential to engage in hydroarylation reactivity ${ }^{57}$; however, we only observed hydroalkoxylation products (ethers) when parasubstituted phenols $\left(\mathrm{CF}_{3}, \mathrm{~F}, \mathrm{Cl}, \mathrm{Br}\right)$ and norbornene (23) were treated with $\mathrm{D} / \mathrm{AgOTf}$ at either room temperature or $50{ }^{\circ} \mathrm{C}$. In contrast, bis-ortho-hydroarylation products were 


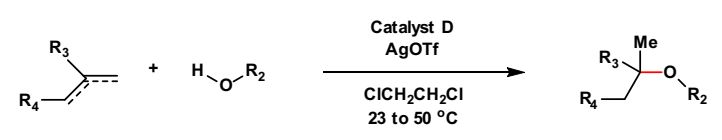

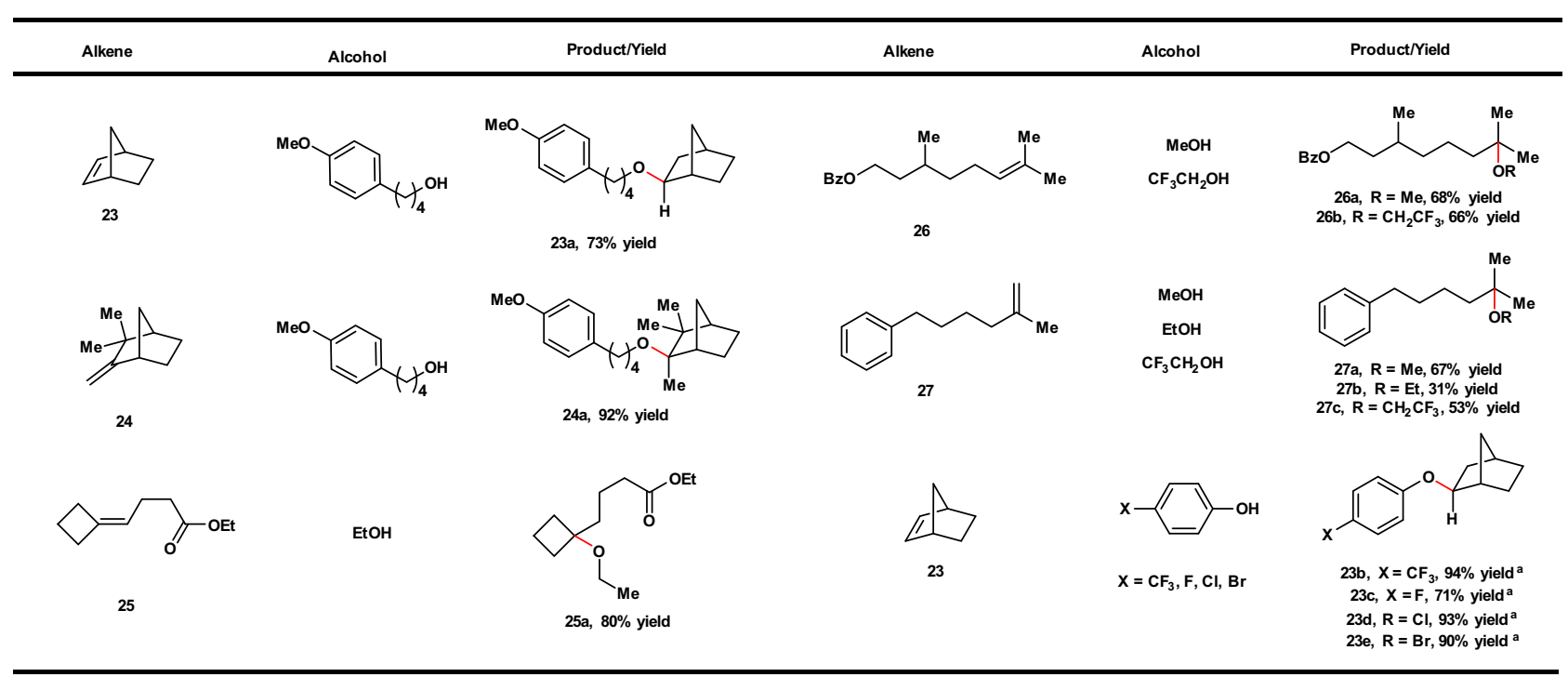

Fig. 4 Substrate scope for intermolecular hydroalkoxylation. General conditions: catalyst $\mathbf{D}(5 \mathrm{~mol} \%), \mathrm{AgOTf}(6 \mathrm{~mol} \%), 50^{\circ} \mathrm{C}, 16-24 \mathrm{~h}$. Yields of isolated products were given. ${ }^{a}$ Catalyst $\mathbf{D}(2 \mathrm{~mol} \%), \mathrm{AgOTf}(3 \mathrm{~mol} \%), 23^{\circ} \mathrm{C}, 24 \mathrm{~h}$.

exclusively generated when triflic acid $(\mathrm{TfOH})$ alone was used as the catalyst (See Supplementary Information for further details). These results suggest a distinct mechanistic pathway for our catalytic system, different from that of a Brønsted acid-catalyzed hydroalkoxylation.

Substrate scope for hydroamination. The "donor-acceptor"-type Pt catalysts not only are capable of catalyzing hydroalkoxylation but can also affect the hydroamination of unactivated alkenes in generally good yields. As compiled in Fig. 5, the catalyst E, even used at lower loading of $1 \mathrm{~mol} \%$, was shown to be capable of effecting intramolecular alkene hydroamination with sulfonamides at ambient temperatures, providing various nitrogen-heterocycles that are important structural motifs in naturally occuring and pharmaceuticals. A wide range of alkene substitution patterns is tolerated, including 1,1-disubstituted (Fig. 5, entries 1-8), 1,2disubstituted (Fig. 5, entry 9), mono-substituted (Fig. 5, entries 10 and 11), and trisubstituted alkenes (Fig. 5, entries 12-14). The relative stereochemistry of 41a was unambiguously confirmed by X-ray crystallography (Fig. 5, entry 14). Next, we examined the viability of more difficult intermolecular alkene aminations with $p$ toluenesulfonamide, ( $p$-tolylsulfonyl)methylamine, $N$-tosyl-4methoxyaniline, and methanesulfonamide (Fig. 6). A number of alkene substitution patterns were accommodated, including trisubstituted (Fig. 6, entries 1-4), terminal (Fig. 6, entries 5-7), and 1,2-disubstituted alkenes (Fig. 6, entries 8 and 9). Both cyclic and acyclic alkene partners can be aminated successfully. The structure of $23 \mathbf{f}$ was verified by X-ray crystallography.

Asymmetric hydroalkoxylation and hydroamination. We then explored the catalytic asymmetric hydroalkoxylation ${ }^{58-61}$ and hydroamination ${ }^{62-66}$ with the "donor-acceptor" catalytic system. Various chiral Pt-complexes generated in situ from chiral bisphosphine platinum dichlorides with electron-deficient tris (3,4,5-trifluorophenyl)phosphine were examined in the reaction of 21 and 2 under standard conditions. Disappointingly, none of the chiral Pt catalysts produced enantioselectivities (see further details in Supplementary Information). As shown in Fig. 7, we envisioned that a bi-functional catalysis where the monodentate ligand has a basic group that can form hydrogen bonding with the nucleophile would assist recognition of prochiral faces of the alkenes $^{59,67}$. To our delight, catalysts $\mathbf{N}$ and $\mathbf{M}$ bearing $(R)$ BINAP and $(R)$-Difluorphos as "donor" ligands and the monodentate "acceptor" ligand with a hydrogen-bonding site induced moderate enantioselectivities in both hydroalkoxylation of $\mathbf{2 1}$ and hydroamination of 2 .

Mechanistic studies. Recently, several groups have independently demonstrated that $\mathrm{TfOH}$ can catalyze the additions of oxygenand nitrogen-based nucleophiles to simple alkenes with comparable efficiency/selectivity as some metal triflates ${ }^{52-55}$. The aforementioned reports raised the question of a competitive acidcatalyzed pathway when metal triflates are employed. Therefore, we elected to perform a detailed analysis of the possible mechanistic pathways for the "donor-acceptor" Pt-catalyzed hydroalkoxylation of alkenes.

The mechanistic study commenced with monitoring the reaction of norbornene and 4-trifluromethylphenol catalyzed by $\mathrm{D}$ and AgOTf in deuterated dichloromethane at $23^{\circ} \mathrm{C}$ by ${ }^{31} \mathrm{P}$ NMR (Fig. 8 and please also see Supplementary Fig. 6 for corresponding ${ }^{1} \mathrm{H}$ NMRs). When AgOTf ( 2 equiv.) was added into catalyst $\mathrm{D}$ (1 equiv.), ${ }^{31} \mathrm{P} \mathrm{NMR}$ revealed the appearance of three new peaks at $\delta-33.5\left(\mathrm{~d},{ }^{1} J_{\mathrm{Pt}-\mathrm{P}}=4511 \mathrm{~Hz}\right),-22.5\left(\mathrm{~d},{ }^{1} J_{\mathrm{Pt}-\mathrm{P}}\right.$ $=4018 \mathrm{~Hz}$ ), and 14.4 (s, broad) ppm, respectively (Fig. $8 \mathrm{~b}$ ). The peak at $\delta-22.5 \mathrm{ppm}$ was proposed to be the dinuclear complex $\mathbf{F}$ that can be generated independently by mixing 1 equivalent of dmfpfPtCl 2 with 1 equivalent of AgOTf (Fig. 8e), which was also confirmed by ESI-MS analysis $\left([\mathrm{F}-2 \mathrm{OTf}]^{2+}, \mathrm{m} / \mathrm{z}=800.0137\right)$. We were able to grow the single crystal of the corresponding DPPF derived dinucleor Pt complex and confirmed its structure by Xray. Please see Supplementary Information for details. The peak at $\delta-33.5 \mathrm{ppm}$ was proposed to be complex $\mathbf{G}$ that can be prepared independently by mixing 1 equivalent of $\mathrm{dmfpfPtCl}_{2}$ with 2 equivalents of AgOTf (Fig. 8f). Complex $\mathbf{G}$ is moisture sensitive and when we attempted to grow single crystal of it, we only obtained $\left[(\mathrm{P} \sim \mathrm{P}) \mathrm{Pt}\left(\mathrm{H}_{2} \mathrm{O}\right)_{2}\right]^{2+}\left({ }^{-} \mathrm{OTf}\right)_{2}$. Please see Supplementary 


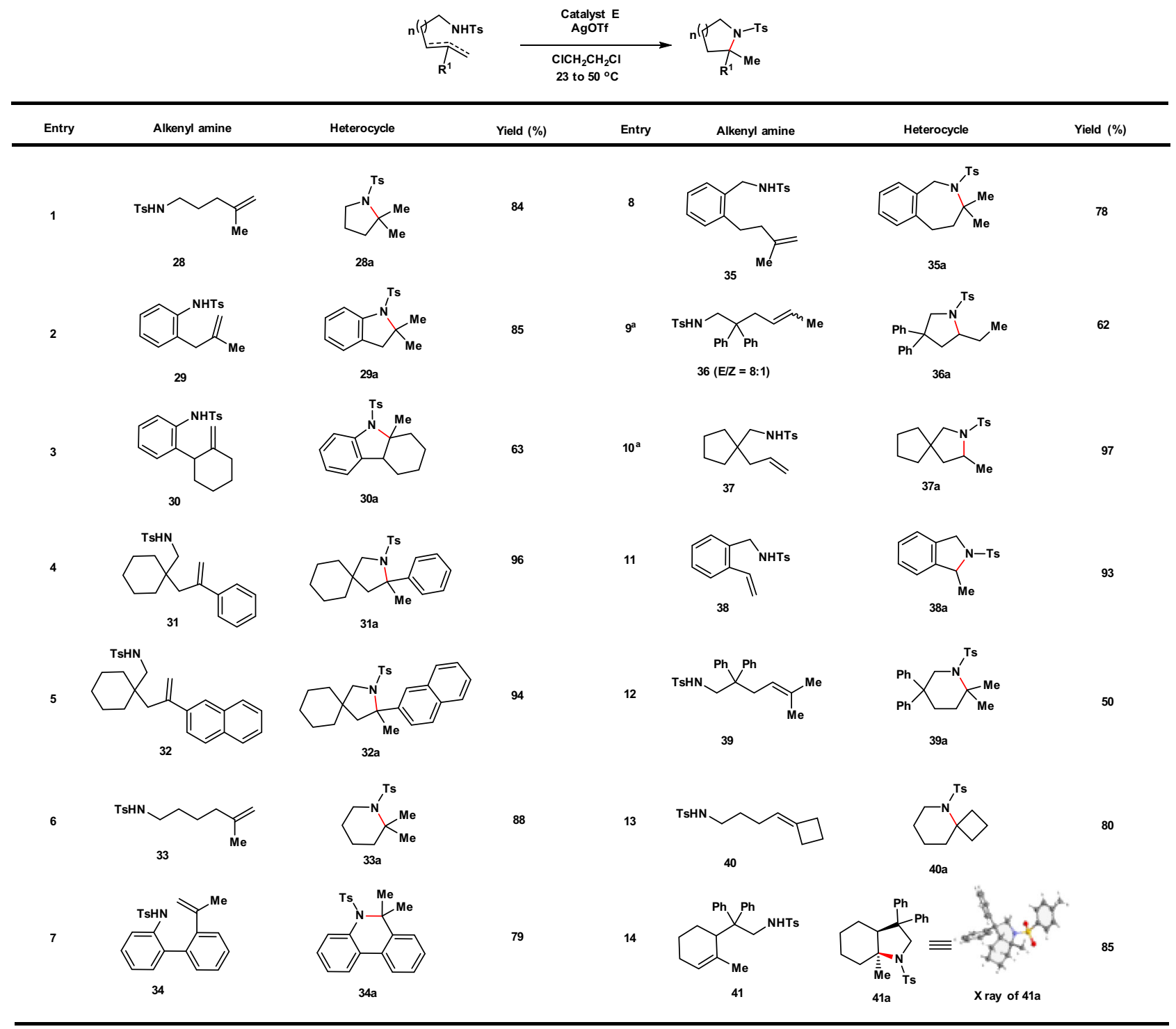

Fig. 5 Substrate scope for intramolecular hydroamination. General conditions: catalyst $\mathbf{E}(1 \mathrm{~mol} \%), \operatorname{AgOTf}(2 \mathrm{~mol} \%), 23^{\circ} \mathrm{C}, 24 \mathrm{~h}$. Yields of isolated products were given. ${ }^{\mathrm{a} C}$ atalyst $\mathbf{E}(5 \mathrm{~mol} \%), \mathrm{AgOTf}(6 \mathrm{~mol} \%), 50^{\circ} \mathrm{C}, 48 \mathrm{~h}$.

Information for details. We also found that more AgOTf leads to more complex $\mathbf{G}$ appearing at $\delta-33.5\left(\mathrm{~d},{ }^{1} J_{\mathrm{Pt}-\mathrm{P}}=4511 \mathrm{~Hz}\right)$ in ${ }^{31} \mathrm{P}$ NMR; however, too much AgOTf did not lead to more complex G (Supplementary Figs. 4, 7, 10, and 12 for adding 1, 2, 5, and 50 equiv. of AgOTf, respectively), indicating that there might be equilibrium between catalyst $\mathbf{D}$ and complex $\mathbf{G}$ in the presence of AgOTf. The third new peak at $\delta 14.4 \mathrm{ppm}$ might belong to silverphosphine complexes, such as $\left[\left(\mathrm{Ar}_{3} \mathrm{P}\right)_{\mathrm{x}} \mathrm{AgOTf}\right]_{\mathrm{n}}(\mathbf{H})$ with ${ }^{19} \mathrm{~F}$ signals at $\delta-78.9(\mathrm{~s}),-131.6(\mathrm{~d}, J=21.3 \mathrm{~Hz})$, and $-154.8(\mathrm{t}, J=$ $20.8 \mathrm{~Hz}$ ) ppm (Supplementary Fig. 5). Then 4 equivalents of norbornene were added to the above solution which led to the rapid disappearance of complexes F, G, and $\mathbf{H}$ (Fig. 8c). Finally, when 4-trifluoromethylphenol was added, ${ }^{1} \mathrm{H}$ NMR confirmed that the hydroalkoxylation product $\mathbf{2 3} \mathbf{b}$ was formed with the concurrent regeneration of the three complexes $\mathbf{F}, \mathbf{G}$, and $\mathbf{H}$ (Fig. 8d and please also see the ${ }^{1} \mathrm{H}$ NMR in Supplementary Fig. 6). These results indicate that either one or both of complexes $\mathbf{F}$ and $\mathbf{G}$ might be the catalytic active species (Complex $\mathbf{H}$ has been excluded as a catalytic active specie; please see the control experiments in Supplementary Table 1, entry 24). Therefore, we would like to monitor the reaction pathways of the hydroalkoxylation catalyzed by complexes $\mathbf{F}$ and $\mathbf{G}$, respectively.
As depicted in Supplementary Fig. 19a, b, the dinuclear complex $\mathbf{F}$ was immediately converted to the original catalyst $\mathbf{D}$ as soon as the monodentate ligand, tris(3,4,5-trifluorophenyl) phosphine, was added. Further treating the mixture with norbornene and 4-trifluromethylphenol did not lead to any change in ${ }^{31} \mathrm{P}$ and ${ }^{1} \mathrm{H}$ NMR (Supplementary Figs. 19c, $\mathrm{d}$ and 18). We have also conducted an experiment to monitor the reaction of complex F (1 equiv.) with norbornene (4 equiv.) and 4trifluromethylphenol (4 equiv.) in the absence of the monodentate tris(3,4,5-trifluorophenyl)phosphine ligand by ${ }^{1} \mathrm{H}$ and ${ }^{31} \mathrm{P}$ NMRs, and we observed the formation of some hydroalkoxylation product 23b (about 50\% yield) after $1 \mathrm{~h}$ (Please see Supplementary Figs. 20 and 21). Another control experiment has been conducted to investigate the catalytic activity of complex $\mathbf{F}$ (Entry 1, Supplementary Table 7), where no intramolecular hydroalkoxylation of 1 proceeds in the presence of complex $\mathbf{F}$. These results together suggest that complex $\mathbf{F}$ will more readily react with the monodentate ligand to form catalyst $\mathbf{D}$ than catalyze the hydroxylation reaction in the present system.

We then turned our attention to monitoring the hydroalkoxylation catalyzed by the other potential catalytic active specie complex G (Fig. 9). However, we were unable to prepare pure 

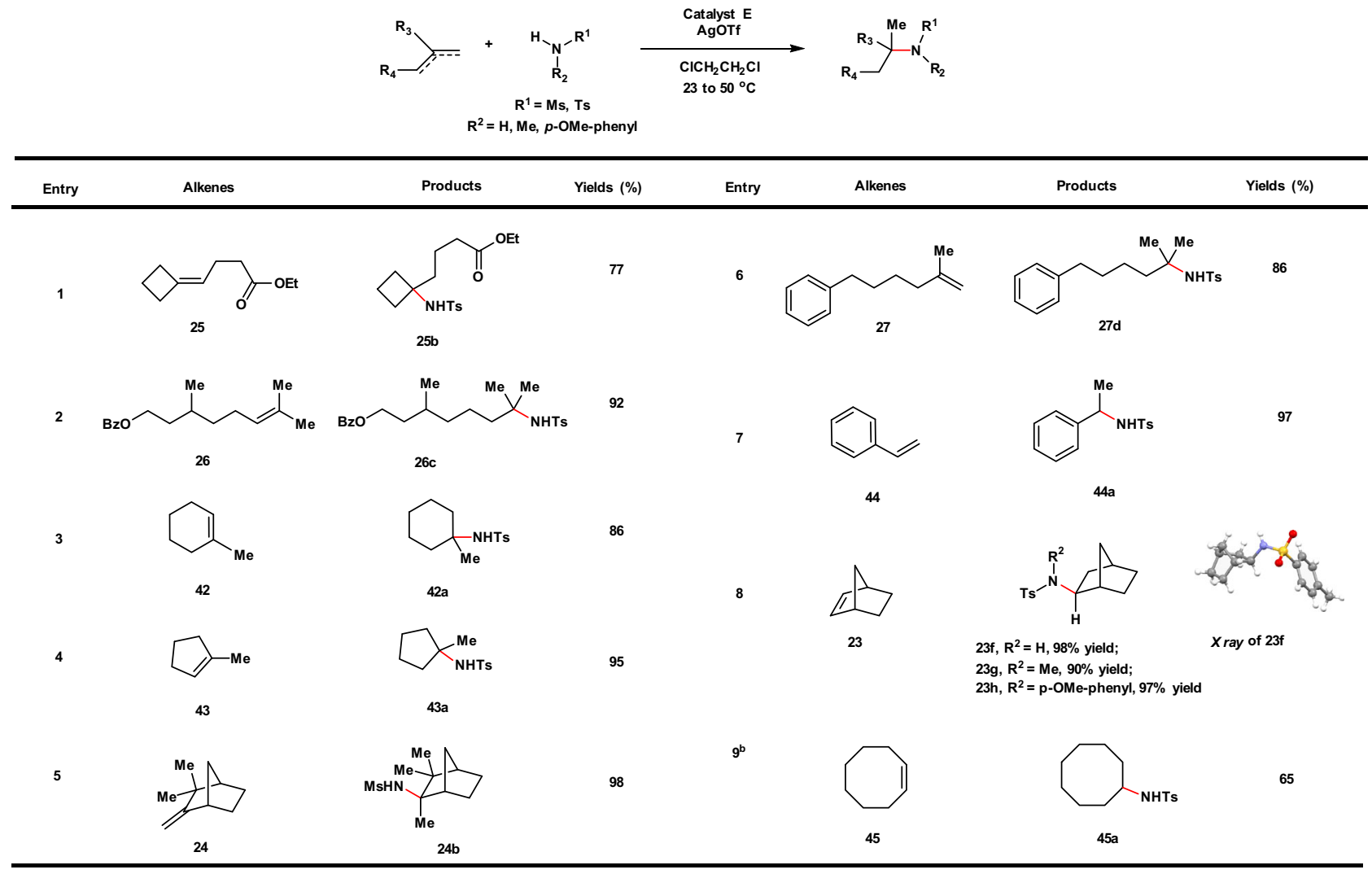

Fig. 6 Substrate scope for intermolecular hydroamination. General conditions: catalyst $\mathbf{E}(2 \mathrm{~mol} \%), \mathrm{AgOTf}(4 \mathrm{~mol} \%), 23^{\circ} \mathrm{C}, 8-24 \mathrm{~h}$. Yields of isolated products were given. ${ }^{a}$ Catalyst $\mathbf{E}(5 \mathrm{~mol} \%)$, AgOTf $(6 \mathrm{~mol} \%), 50^{\circ} \mathrm{C}, 48 \mathrm{~h}$. Ts tosyl, Ms mesyl.

complex G with 1.1'-[bis(5-methyl-2-furanyl)phosphine]ferrocene as the bidentate donor ligand ${ }^{21}$ : the dinuclear complex $\mathbf{F}$ was always inevitable. As shown in Fig. 9a, treating (dmfpf) $\mathrm{PtCl}_{2}$ with 4 equivalents of AgOTf provides a mixture of $\mathbf{G}$ and $\mathbf{F}$ with a relatively high ratio (7:1), which was then filtered off $\mathrm{AgCl}$ and used for the following experiment. $\mathrm{AgCl}$ will re-enter into the solution and react with complex $\mathbf{G}$ to make catalyst $\mathbf{D}$ in the presence of monodentate ligand. When the monodentate ligand was added into the above mixture (Fig. 9b), except catalyst $\mathbf{D}$ that might be generated from the dinuclear complex $\mathbf{F}$, a new complex appearing at $\delta 25.8\left(\mathrm{~d},{ }^{2} \mathrm{~J}_{\mathrm{P}-\mathrm{P}}=411 \mathrm{~Hz},{ }^{1} \mathrm{JPt}_{\mathrm{Pt} \mathrm{P}}=2584 \mathrm{~Hz}\right),-6.2(\mathrm{~d}$, $\left.{ }^{2} J_{\mathrm{P}-\mathrm{P}}=411,{ }^{1} J_{\mathrm{Pt}-\mathrm{P}}=2745 \mathrm{~Hz}\right),-29.9\left(\right.$ broad, $\left.{ }^{1} J_{\mathrm{Pt}-\mathrm{P}}=4289 \mathrm{~Hz}\right)$ ppm was proposed to be $\mathbf{P}$ with both the electron-donating bidentate and electron-deficient monodetate ligands coordinating to the Pt center (Please also see the details in the Supplementary Information for the synthesis of complex $\mathbf{P}$ ). Then 4 equivalents of norbornene were added, and a new group of peaks at $\delta 33.6$ $\left(\mathrm{dd},{ }^{2} J_{\mathrm{P}-\mathrm{P}}=410,22 \mathrm{~Hz},{ }^{1} J_{\mathrm{Pt}-\mathrm{P}}=3075\right),-12.6\left(\mathrm{dd},{ }^{2} \mathrm{~J}_{\mathrm{P}-\mathrm{P}}=411,23\right.$ $\left.\mathrm{Hz},{ }^{1} J_{\mathrm{Pt}-\mathrm{P}}=3463\right),-17.2\left(\mathrm{t},{ }^{2} J_{\mathrm{P}-\mathrm{P}}=22 \mathrm{~Hz},{ }^{1} J_{\mathrm{Pt}-\mathrm{P}}=1873\right) \mathrm{ppm}$ were observed in ${ }^{31} \mathrm{P}$ NMR (Fig. 9c). Because they all disappeared after adding 4-trifluoromethylphenol (Fig. 9d, and ${ }^{1} \mathrm{H}$ NMR in Supplementary Fig. 25 showed the complete formation of hydroalkoxylation product $\mathbf{2 3 \mathbf { b }}$ ), we proposed that this group of new peaks belongs to an alkene-bound "donor-acceptor"-type intermediate $\mathbf{J}$. Notably, filtrating $\mathrm{AgCl}$ from the reaction media allowed us to identify the key intermediate $\mathbf{J}$, whereas it is no clearly visible when the filtration is not carried out (Supplementary Fig. 23). AgCl will re-enter into the solution and react with complex $\mathbf{G}$ to make catalyst $\mathbf{D}$ in the presence of monodentate ligand.

Based on the NMR experiments, we propose a plausible mechanism for "donor-acceptor"-type Pt complex catalyzed hydroalkoxylation of unactivated alkenes (Fig. 10). When catalyst
D was treated with AgOTf, both of the monophosphine ligand and chloride ion dissociate from the Pt center and react with AgOTf to generate complex $\mathbf{H}$ and $\mathrm{AgCl}$, respectively. Therefore, two Pt-complexes $\mathbf{F}$ and $\mathbf{G}$ were formed simultaneously. The silver-phosphine complex $\mathbf{H}$ reacts with external alkenes to form silver-alkene adducts, such as complex I, releasing the monophosphine ligand that will react with the dinuclear complex $\mathbf{F}$ to regenerate the original catalyst $\mathbf{D}$ (Fig. 10, catalytic cycle A); when the hydroalkoxylation reaction was finished and all the alkenes were consumed, AgOTf was released from complex I, and therefore catalyst $\mathbf{D}$ was converted to dinuclear $\mathbf{F}$ again. Complex G, in the presence of alkenes, reacts with electrondeficient monophosphine to form a 16-electron, "donor-acceptor"-type Pt complex J either directly or through complex $\mathbf{P}$ (Fig. 10, catalytic cycle B). Nucleophilic attack on the bound alkene by a free alcohol provides complex K. Proton transfer thereafter provides the hydroalkoxylation product and regenerates complexes $\mathbf{G}$ (or $\mathbf{P}$ ) and $\mathbf{H}$. Another possible competitive pathway for the catalytic active species $\mathbf{G}$ and $\mathbf{P}$ includes regeneration of the original catalyst $\mathbf{D}$ in the presence of $\mathrm{AgCl}$ (Fig. 10, catalytic cycle C).

In summary, we have described herein the developed "donor-acceptor"-type platinum catalysts that are superior in effecting both hydroalkoxylation and hydroamination with respect to mild reaction conditions and generality in substrate scope. Mechanistic studies suggested a plausible pathway that includes an unusual dissociation/re-association of the electrondeficient monophosphine ligand to generate an alkene bound "donor-acceptor" type intermediate. Efforts to improve the reactivity and enantioselectivity of the chiral platinum catalysts based on bi-functional catalysis for asymmetric hydrofunctionalization will be the subject of future studies. 


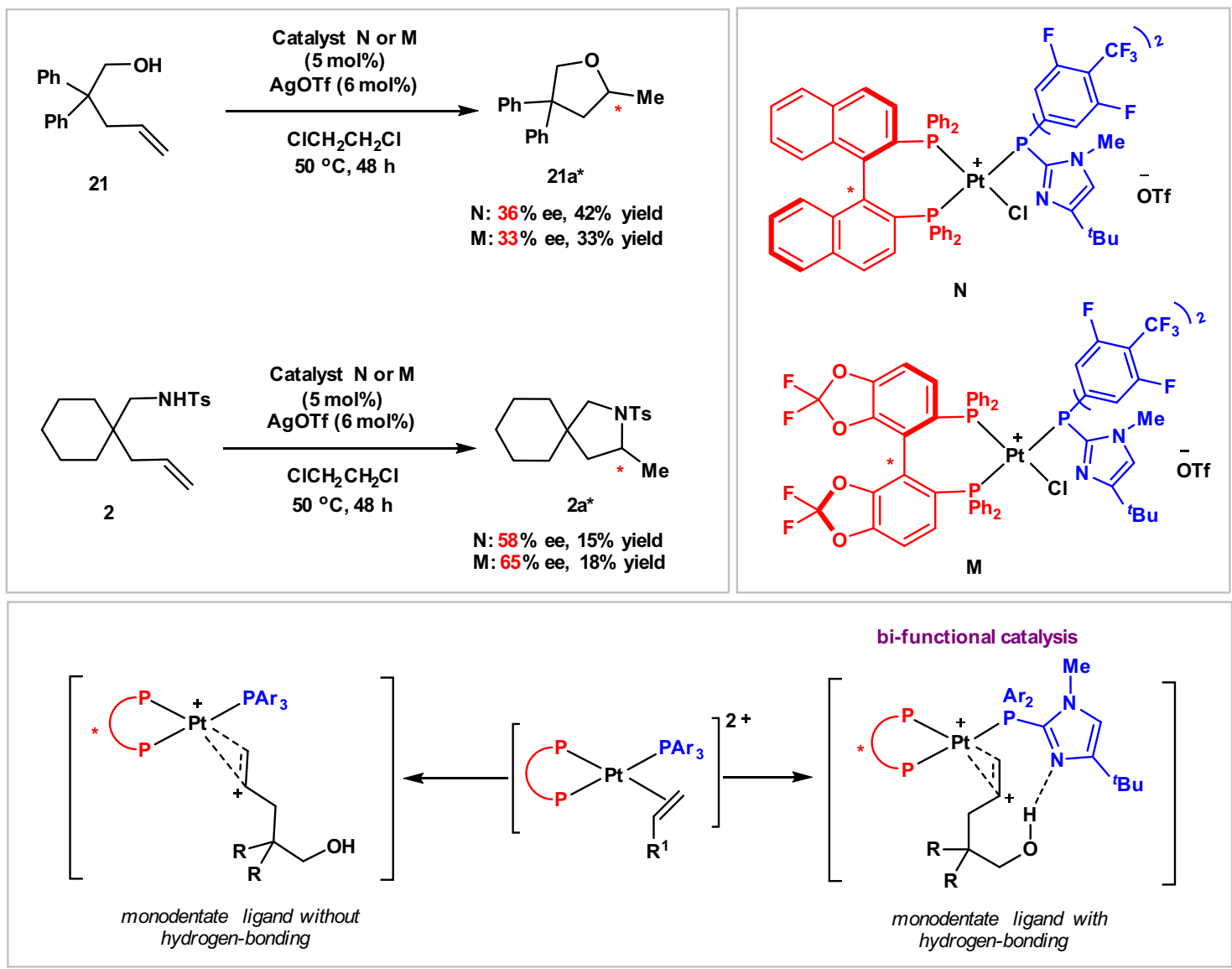

Fig. 7 Development of bi-functional catalysis for catalytic asymmetric hydroalkoxylation and hydroamination. a Pt-catalyzed asymmetric intermolecular hydroalkoxylation and hydroamination of unactivated alkenes. b Catalysts $\mathbf{N}$ and $\mathbf{M}$. c Bi-functional catalysis for asymmetric hydroalkoxylation and hydroamiantion.

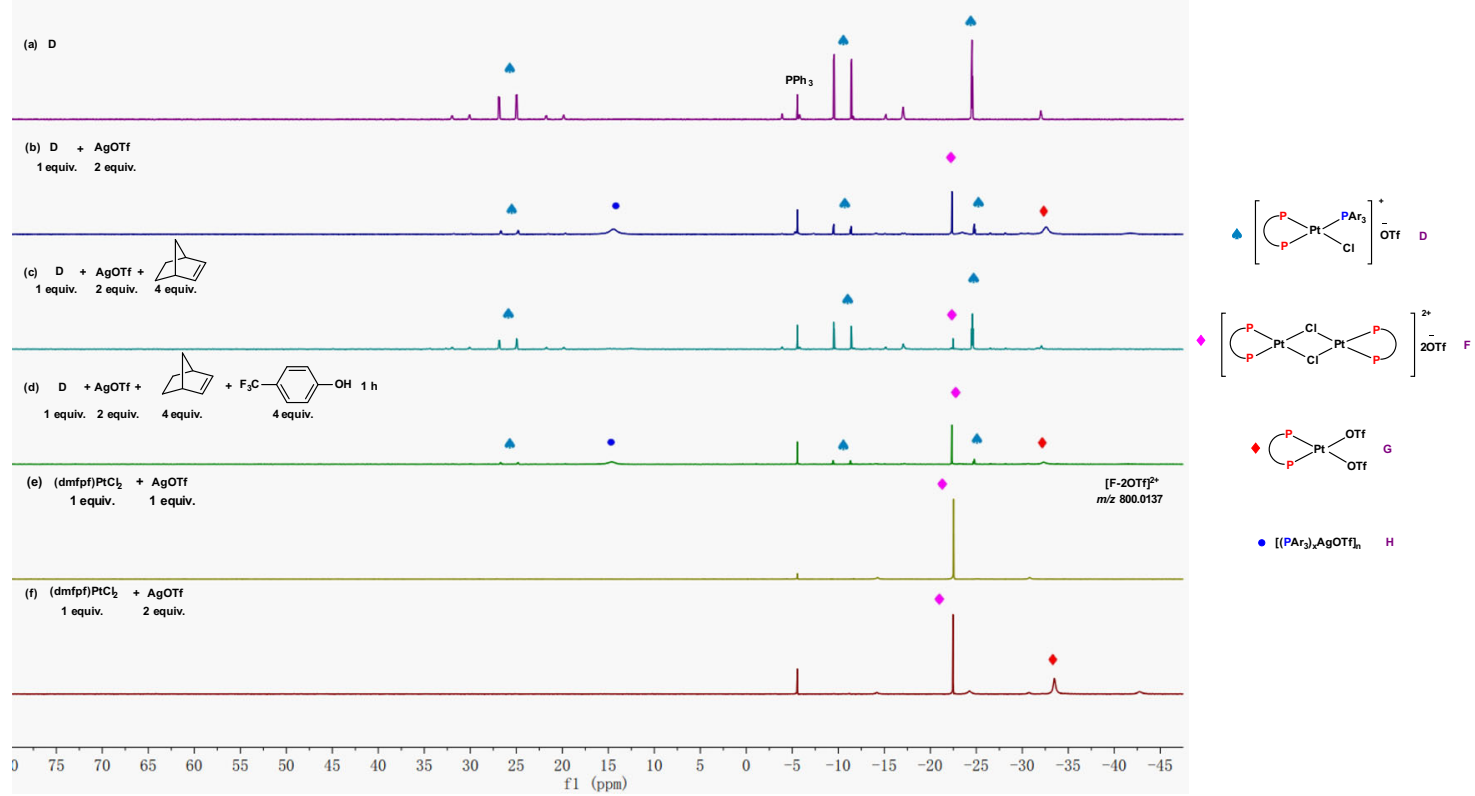

Fig. $8{ }^{31} \mathrm{P}$ NMR spectra for monitoring the reaction of catalyst $\mathrm{D}+\mathrm{AgOTf}+$ norbornene + 4-trifluromethylphenol $\left(\mathrm{PPh}_{\mathbf{3}}\right.$ was used as an external standard). a ${ }^{31}$ P NMR spectra of complex D. b ${ }^{31}$ P NMR spectra of a mixture of complex D (1 equiv.) and AgOTf (2 equiv.). c ${ }^{31} \mathrm{P}$ NMR spectra of a mixture of complex D (1 equiv.), AgOTf (2 equiv.), and norbornene (4 equiv.). d ${ }^{31}$ P NMR spectra of a mixture of complex D (1 equiv.), AgOTf (2 equiv.), norbornene (4 equiv.), and 4-trifluoromethylphenol (4 equiv.). e ${ }^{31} \mathrm{P} \mathrm{NMR}$ spectra of a mixture of (dmfpf) $\mathrm{PtCl}_{2}\left(1\right.$ equiv.), and $\mathrm{AgOTf}\left(1 \mathrm{equiv}\right.$.). $\mathbf{f}^{31 \mathrm{P} \mathrm{NMR}}$ spectra of a mixture of (dmfpf) $\mathrm{PtCl}_{2}$ (1 equiv.), and $\mathrm{AgOTf}$ (2 equiv.). Specifically, (dmfpf) $\mathrm{PtCl}_{2}: 1.1^{\prime}$-[bis(5-methyl-2-furanyl)phosphine]ferrocene platinum dichloride; AgOTf: silver triflate. 


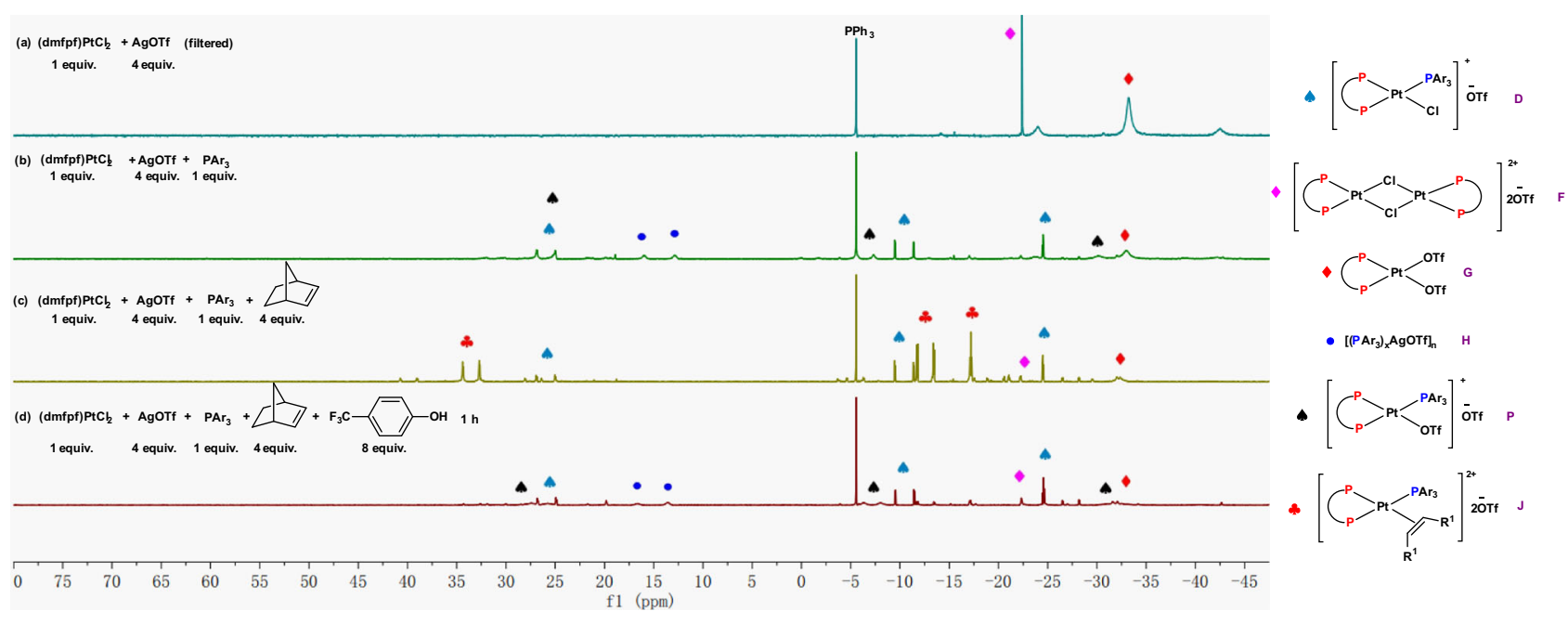

Fig. 9 31P NMR spectra for the reaction of $\mathbf{d m f p f P t C l}+$ AgOTf (4 equiv.) $+\mathrm{PAr}_{\mathbf{3}}+$ norbornene + 4-trifluromethylphenol ( $\mathrm{PPh}_{\mathbf{3}}$ was used as an external standard). a ${ }^{31} \mathrm{P} \mathrm{NMR}$ spectra of a mixture of (dmfpf) $\mathrm{PtCl}_{2}$ (1 equiv.) and $\mathrm{AgOTf}$ (4 equiv.) after filtration. b ${ }^{31} \mathrm{P}$ NMR spectra of a mixture of (dmfpf) $\mathrm{PtCl}_{2}$ (1 equiv.), AgOTf (4 equiv), and tris(3,4,5-trifluorophenyl)phosphane (1 equiv.) after filtered. c ${ }^{31} \mathrm{P}$ NMR spectra of a mixture of (dmfpf)PtCl 2 (1 equiv.), AgOTf (4 equiv.), tris(3,4,5-trifluorophenyl)phosphane (1 equiv.), and norbornene (4 equiv.) after filtered. $\mathbf{d}$ 31P NMR spectra of a mixture of (dmfpf) $\mathrm{PtCl}_{2}$ (1 equiv.), AgOTf (4 equiv.), tris(3,4,5-trifluorophenyl)phosphane (1 equiv.), norbornene (4 equiv.), and 4-trifluoromethylphenol (8 equiv.). Specifically, (dmfpf) $\mathrm{PtCl}_{2}: 1.1^{\prime}$-[bis(5-methyl-2-furanyl)phosphine]ferrocene platinum dichloride; AgOTf: silver triflate; $\mathrm{PAr}_{3}$ : tris(3,4,5-trifluorophenyl) phosphine.

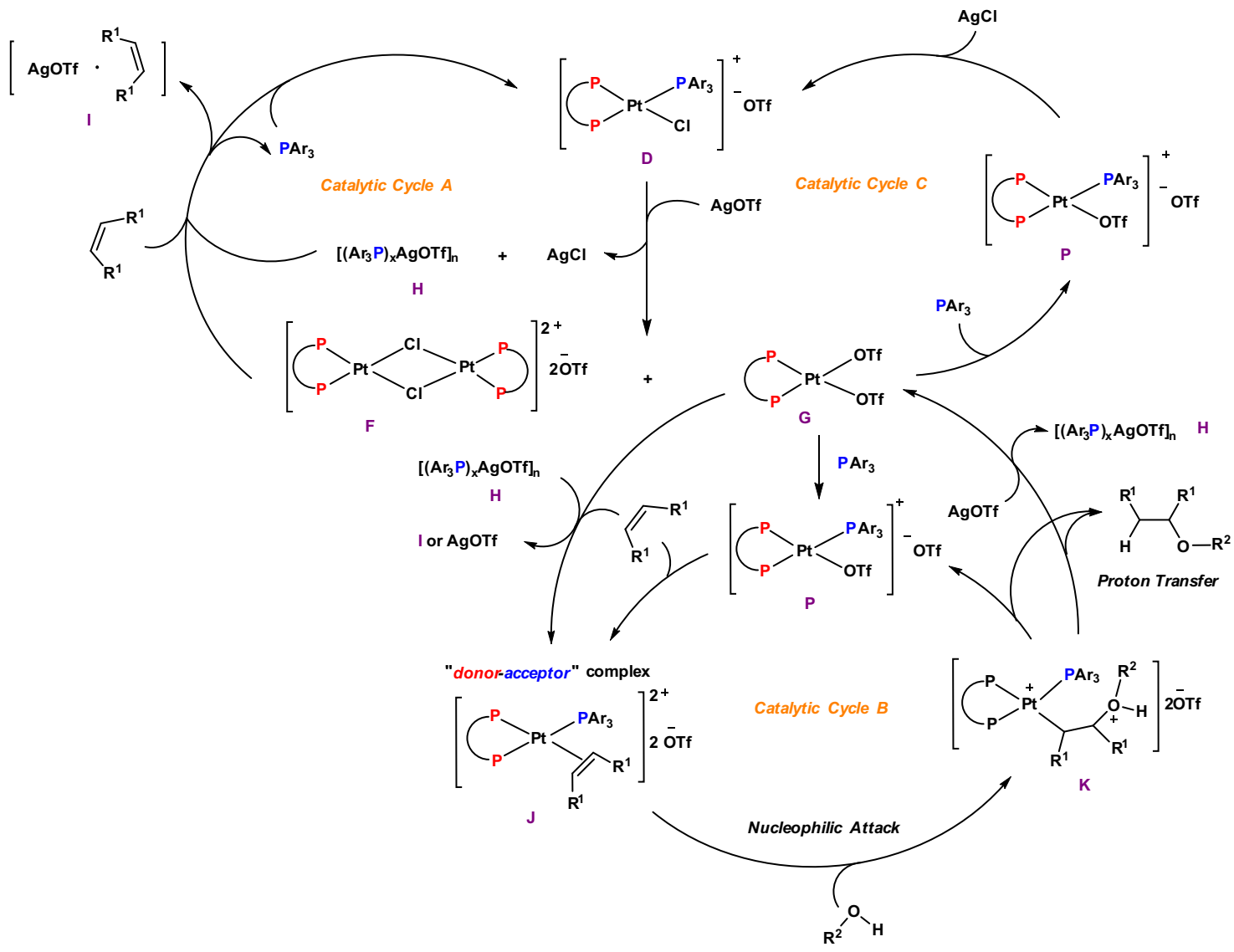

Fig. 10 Proposed mechanism for "donor-acceptor" Pt complex catalyzed hydroalkoxylation of unactivated alkenes. Specifically, D: Catalyst; F: a dinuclear intermediate after Pt-P bond dissociation; G: an intermediate after Pt-Cl and Pt-P bonds dissociation; $\mathbf{H}$ : a silver-phosphine complexe; I: a silveralkene complexe; J: an alkene-bound Pt (II) intermediate; $\mathbf{K}$ : transition state for nucleophilic attack of an alcohol to complex $\mathbf{J} ; \mathbf{P}$ : an intermediate after Pt-Cl bond dissociation. 


\section{Methods}

General procedure for preparing "donor-acceptor" Pt catalyst. In an argonfilled glovebox, to a $4 \mathrm{~mL}$ vial with a magnetic stir bar were added ( $\mathrm{dmfpf}) \mathrm{PtCl}_{2}$ (100 mg, $0.12 \mathrm{mmol}$ ), silver trifluoromethanesulfonate $(31 \mathrm{mg}, 0.12 \mathrm{mmol}, 1.0$ equiv.), monophosphine ligand ( $0.13 \mathrm{mmol}, 1.05$ equiv.), and $\mathrm{CH}_{2} \mathrm{Cl}_{2}(2 \mathrm{~mL})$. Then the vial was taken outside of the glovebox and was stirred at $23^{\circ} \mathrm{C}$ for $12 \mathrm{~h}$. The orange solution was filtered and $\mathrm{CH}_{2} \mathrm{Cl}_{2}$ was evaporated to provide orange solid, which was recrystallized in $\mathrm{CH}_{2} \mathrm{Cl}_{2}$ and hexane to give yellow precipitate.

General procedure for intramolecular hydroalkoxylation. In an argon-filled glovebox, to a $4 \mathrm{~mL}$ vial with a magnetic stir bar were added catalyst $\mathbf{C}(0.001$ $\mathrm{mmol}, 1 \mathrm{~mol} \%)$, silver trifluoromethanesulfonate $(0.002 \mathrm{mmol}, 2 \mathrm{~mol} \%)$, the substrate $(0.1 \mathrm{mmol})$, and $\mathrm{ClCH}_{2} \mathrm{CH}_{2} \mathrm{Cl}(1 \mathrm{~mL})$. Then the vial was taken outside of the glovebox and stirred at $23^{\circ} \mathrm{C}$ for $24 \mathrm{~h}$. The mixture was diluted with $\mathrm{CH}_{2} \mathrm{Cl}_{2}$, filtered through a pad of celite and concentrated. The residue was purified by silica gel chromatography to give the desired product.

General procedure for intermolecular hydroalkoxylation. In an argon-filled glovebox, to a $4 \mathrm{~mL}$ vial with a magnetic stir bar were added catalyst $\mathbf{D}(0.01 \mathrm{mmol}$, $5 \mathrm{~mol} \%)$, silver trifluoromethanesulfonate $(0.012 \mathrm{mmol}, 6 \mathrm{~mol} \%)$, alkenes $(0.2$ mmol), alcohols ( $0.3 \mathrm{mmol}, 1.5$ equiv.), and $\mathrm{ClCH}_{2} \mathrm{CH}_{2} \mathrm{Cl}(1 \mathrm{~mL})$. Then the vial was taken outside of the glovebox and stirred at $50{ }^{\circ} \mathrm{C}$ for $16 \mathrm{~h}$. The reaction mixture was cooled to room temperature $\left(23^{\circ} \mathrm{C}\right)$ and diluted with $\mathrm{CH}_{2} \mathrm{Cl}_{2}$, filtered through a pad of celite and concentrated in vacue. The residue was purified by silica gel chromatography to give the desired product.

General procedure for intramolecular hydroamination. To a $4 \mathrm{~mL}$ vial equipped with a magnetic stir bar were added the catalyst $\mathbf{E}(0.001 \mathrm{mmol}, 1 \mathrm{~mol} \%)$, silver trifluoromethanesulfonate $(0.002 \mathrm{mmol}, 2 \mathrm{~mol} \%)$, and $\mathrm{ClCH}_{2} \mathrm{CH}_{2} \mathrm{Cl}(1.0 \mathrm{~mL})$ in an argon-filled glovebox. The mixture was stirred at $23^{\circ} \mathrm{C}$ for $1 \mathrm{~h}$. Then to the mixture was added a solution of $37(30.7 \mathrm{mg}, 0.1 \mathrm{mmol})$ in $\mathrm{ClCH}_{2} \mathrm{CH}_{2} \mathrm{Cl}(0.5 \mathrm{~mL})$. The vial was taken outside of the glovebox and stirred at $23^{\circ} \mathrm{C}$ for $24 \mathrm{~h}$. The mixture was diluted with $\mathrm{CH}_{2} \mathrm{Cl}_{2}$ and concentrated under reduced pressure. The residue was purified by flash chromatography to afford the desired product.

General procedure for intermolecular hydroamination. In an argon-filled glovebox, to a $4 \mathrm{~mL}$ vial with a magnetic stir bar were added catalyst $\mathbf{E}(0.002 \mathrm{mmol}, 2$ mol\%), silver trifluoromethanesulfonate $(1.0 \mathrm{mg}, 0.004 \mathrm{mmol}, 4 \mathrm{~mol} \%)$, alkenes $(0.1 \mathrm{mmol})$, sulfonamide $(0.15 \mathrm{mmol}, 1.5$ equiv. $)$, and $\mathrm{ClCH}_{2} \mathrm{CH}_{2} \mathrm{Cl}(0.7 \mathrm{~mL})$. Then the vial was taken outside of the glovebox and stirred at 23 or $50{ }^{\circ} \mathrm{C}$ for $6-48 \mathrm{~h}$. The reaction mixture was diluted with $\mathrm{CH}_{2} \mathrm{Cl}_{2}$, filtered through a pad of celite and concentrated. The residue was purified by silica gel chromatography to afford the desired product.

\section{Data availability}

The data that support the findings of this study are available within the paper and its Supplementary Information files. Raw data are available from the corresponding author on reasonable request. Materials and methods, experimental procedures, characterization data, ${ }^{1} \mathrm{H},{ }^{13} \mathrm{C},{ }^{19} \mathrm{~F},{ }^{31} \mathrm{P}$ NMR spectra, and mass spectrometry data are available in the Supplementary Information. Crystallographic data are available free of charge from the Cambridge Crystallographic Data Centre (https://www.ccdc.cam.ac.uk/) under reference number CCDC 1942024 (catalyst E), CCDC 1945616 (41a), CCDC 1942471 (23f), CCDC 2021353 (catalyst M, in the Supplementary Information), CCDC 2053040 (complex Q, in the Supplementary Information) and CCDC 2053041 (complex $\mathbf{R}$, in the Supplementary Information), respectively.

Received: 23 September 2020; Accepted: 26 February 2021; Published online: 29 March 2021

\section{References}

1. DeSimone, R. W., Currie, K. S., Mitchell, S. A., Darrow, J. W. \& Pippin, D. A. Privileged structures: applications in drug discovery. Comb. Chem. High. Throughput Screen. 7, 473-494 (2004).

2. Elliott, M. C. \& Williams, E. Saturated oxygen heterocycles. J. Chem. Soc. Perkin Trans. 1, 2303-2340 (2001).

3. Hintermann, L. Recent Developments in Metal-Catalyzed Additions of Oxygen Nucleophiles to Alkenes and Alkynes. in C-X Bond Formation (ed Vigalok, A.) 123-155 (Springer, 2010).

4. Qian, H., Han, X. \& Widenhoefer, R. A. Platinum-catalyzed intramolecular hydroalkoxylation of $\gamma$ - and $\delta$-hydroxy olefins to form cyclic ethers. J. Am. Chem. Soc. 126, 9536-9537 (2004).

5. Yang, C.-G. \& He, C. Gold(I)-catalyzed intermolecular addition of phenols and carboxylic acids to olefins. J. Am. Chem. Soc. 127, 6966-6967 (2005).
6. Seo, S., Yu, X. \& Marks, T. J. Intramolecular hydroalkoxylation/cyclization of alkynyl alcohols mediated by lanthanide catalysts. Scope and reaction mechanism. J. Am. Chem. Soc. 131, 263-276 (2009).

7. Hamilton, D. S. \& Nicewice, D. A. Direct catalytic anti-markovnikov hydroetherification of alkenols. J. Am. Chem. Soc. 134, 18577-18580 (2012).

8. Sevov, C. S. \& Hartwig, J. F. Iridium-catalyzed, intermolecular hydroetherification of unactivated aliphatic alkenes with phenols. J. Am. Chem. Soc. 135, 9303-9306 (2013).

9. Haibach, M. C. et al. Olefin hydroaryloxylation catalyzed by pincer-iridium complexes. J. Am. Chem. Soc. 135, 15062-15070 (2013).

10. Shigehisa, H., Aoki, T., Yamaguchi, S., Shimizu, N. \& Hiroya, K. Hydroalkoxylation of unactivated olefins with carbon radicals and carbocation species as key intermediates. J. Am. Chem. Soc. 135, 10306-10309 (2013).

11. Lohr, T. L., Li, Z. \& Marks, T. J. Thermodynamic strategies for C-O bond formation and cleavage via tandem catalysis. Acc. Chem. Res. 49, 824-834 (2016).

12. Marcyk, P. T. \& Cook, S. P. Iron-catalyzed hydroamination and hydroetherification of unactivated alkenes. Org. Lett. 21, 1547-1550 (2019).

13. Discolo, C. A., Touney, E. E. \& Pronin, S. V. Catalytic asymmetric radical-polar crossover hydroalkoxylation. J. Am. Chem. Soc. 141, 17527-17532 (2019).

14. Schluter, J., Blazejak, M., Boeck, F. \& Hintermann, L. Asymmetric hydroalkoxylation of non-activated alkenes: titanium-catalyzed cycloisomerization of allylphenols at high temperatures. Angew. Chem. Int. Ed. 54, 4014-4017 (2015).

15. Müller, T. E. \& Beller, M. Metal-initiated amination of alkenes and alkynes. Chem. Rev. 98, 675-704 (1998)

16. Hong, S. \& Marks, T. J. Organolanthanide-catalyzed hydroamination. Acc. Chem. Res. 37, 673-686 (2004).

17. Müller, T. E., Hultzsch, K. C., Yus, M., Foubelo, F. \& Tada, M. Hydroamination: direct addition of amines to alkenes and alkynes. Chem. Rev. 108, 3795-3892 (2008).

18. Brunet, J. J. et al. The first platinum-catalyzed hydroamination of ethylene. Organometallics 23, 1264-1268 (2004).

19. Bender, C. F. \& Widenhoefer, R. A. Platinum-catalyzed intramolecular hydroamination of unactivated olefins with secondary alkylamines. J. Am. Chem. Soc. 127, 1070-1071 (2005).

20. Johns, A. M., Utsunomiya, M., Incarvito, C. D. \& Hartwig, J. F. A highly active palladium catalyst for intermolecular hydroamination. Factors that control reactivity and additions of functionalized anilines to dienes and vinylarenes. $J$. Am. Chem. Soc. 128, 1828-1839 (2006).

21. McBee, J. L., Bell, A. T. \& Tilley, T. D. Mechanistic studies of the hydroamination of norbornene with electrophilic platinum complexes: the role of proton transfer. J. Am. Chem. Soc. 130, 16562-16571 (2008).

22. Dub, P. A. \& Poli, R. The Pt-catalyzed ethylene hydroamination by aniline: a computational investigation of the catalytic cycle. J. Am. Chem. Soc. 132, 13799-13812 (2010)

23. Liu, Z., Yamamichi, H., Madrahimov, S. T. \& Hartwig, J. F. Rhodium phosphine $-\pi$-arene intermediates in the hydroamination of alkenes. J. Am. Chem. Soc. 133, 2772-2782 (2011).

24. Zhu, S., Niljianskul, N. \& Buchwald, S. L. Enantio- and regioselective CuHcatalyzed hydroamination of alkenes. J. Am. Chem. Soc. 135, 15746-15749 (2013).

25. Nyuyen, T. M. \& Nicewicz, D. A. Anti-markovnikov hydroamination of alkenes catalyzed by an organic photoredox system. J. Am. Chem. Soc. 135, 9588-9591 (2013).

26. Huang, L., Arndt, M., Gooßen, K., Heydt, H. \& Gooßen, L. J. Late transition metal-catalyzed hydroamination and hydroamidation. Chem. Rev. 115, 2596-2697 (2015).

27. Ensign, S. C., Vanable, E. P., Kortman, G. D., Weir, L. J. \& Hull, K. L. Antimarkovnikov hydroamination of homoallylic amines. J. Am. Chem. Soc. 137, 13748-13751 (2015).

28. Musacchio, A. J. et al. Catalytic intermolecular hydroaminations of unactivated olefins with secondary alkyl amines. Science 355, 727-730 (2017).

29. Aaron, T., Scarlett, M. W. \& Matthew, J. G. New strategies for the transitionmetal catalyzed synthesis of aliphatic amines. Chem. Rev. 120, 2613-2692 (2020).

30. Fürstner, A. \& Davies, P. W. Catalytic carbophilic activation: catalysis by platinum and gold $\pi$ acids. Angew. Chem. Int. Ed. 46, 3410-3449 (2007).

31. Chianese, A. R., Lee, S. J. \& Gagné, M. R. Electrophilic activation of alkenes by platinum(II): so much more than a slow version of palladium(II). Angew. Chem. Int. Ed. 46, 4042-4059 (2007).

32. Cao, P. et al. Hydroamination of unactivated alkenes catalyzed by novel platinum(II) $\mathrm{N}$-heterocyclic carbene complexes. Organometallics 31, 921-929 (2012).

33. Liu, C., Bender, C. F., Han, X. \& Widenhoefer, R. A. Platinum-catalyzed hydrofunctionalization of unactivated alkenes with carbon, nitrogen and oxygen nucleophiles. Chem. Commun. 2007, 3607-3618 (2007). 
34. Bender, C. F., Brown, T. J. \& Widenhoefer, R. A. Mechanism of the platinum (II)-catalyzed hydroamination of 4-pentenylamines. Organometallics 35, 113-125 (2016).

35. McBee, J. L. \& Tilley, T. D. Nucleophilic attack of amides onto coordinated ethylene in platinum complexes supported by a chelating pyridyl-pyrrolide ligand: azaplatinacyclobutane and vinylamine complexes. Organometallics $\mathbf{2 9}$, 184-192 (2010).

36. Figg, T. M., Cundari, T. R. \& Gunnoe, T. B. Non-redox oxy-insertion via organometallic baeyer-villiger transformations: a computational hammett study of platinum(II) complexes. Organometallics 30, 3779-3785 (2011).

37. Hoover, J. M., DiPasquale, A., Mayer, J. M. \& Michael, F. E. Platinumcatalyzed intramolecular hydrohydrazination: evidence for alkene insertion into a Pt-N bond. J. Am. Chem. Soc. 132, 5043-5053 (2010).

38. McKeown, B. A. et al. Mechanistic studies of ethylene hydrophenylation catalyzed by bipyridyl Pt(II) complexes. J. Am. Chem. Soc. 133, 19131-19152 (2011).

39. Lavery, C. B., Ferguson, M. J. \& Stradiotto, M. Platinum-catalyzed alkene cyclohydroamination: evaluating the utility of bidentate $\mathrm{P}, \mathrm{N} / \mathrm{P}, \mathrm{P}$ ligation and phosphine-Free catalyst systems. Organometallics 29, 6125-6128 (2010).

40. Feducia, J. A., Campbell, A. N., Doherty, M. Q. \& Gagné, M. R. Modular catalysts for diene cycloisomerization: rapid and enantioselective variants for bicyclopropane synthesis. J. Am. Chem. Soc. 128, 13290-13297 (2006).

41. Zhang, R., Xu, Q., Mei, L.-Y., Li, S.-K. \& Shi, M. A N-heterocyclic carbene (NHC) platinum complex as pre-catalyst for the intramolecular hydroamination of olefins with secondary alkylamines and oxidative amination of $\omega$-alkenic amines. Tetrahedron 68, 3172-3178 (2012).

42. Cao, P. et al. Hydroamination of unactivated alkenes catalyzed by novel platinum(II) N-heterocyclic carbene complexes. Organometallics 31, 921-929 (2012).

43. Rios, P. et al. Isolation of a cationic platinum(II) $\sigma$-silane complex. Angew. Chem. Int. Ed. 57, 3217-3221 (2018).

44. Hahn, C., Cucciolito, M. E. \& Vitagliano, A. Coordinated olefins as incipient carbocations: catalytic codimerization of ethylene and internal olefins by a dicationic Pt(II)-ethylene complex. J. Am. Chem. Soc. 124, 9038-9039 (2002).

45. Geier, M. J. \& Gagné, M. R. Diastereoselective Pt catalyzed cycloisomerization of polyenes to polycycles. J. Am. Chem. Soc. 136, 3032-3035 (2014).

46. Felix, R. J., Leighton, C. M. \& Gagné, M. R. Electrophilic Pt(II) complexes: precision instruments for the initiation of transformations mediated by the cation-olefin reaction. Acc. Chem. Res. 47, 2319-2331 (2014).

47. Hahn, C. Enhancing electrophilic alkene activation by increasing the positive net charge in transition-metal complexes and application in homogeneous catalysis. Chem. Eur. J. 10, 5888-5899 (2004).

48. Ríos, P., Rodríguez, A. \& Conejero, S. Enhancing the catalytic properties of well-defined electrophilic platinum complexes. Chem. Commun. 56, 5333-5349 (2020).

49. Xing, X. et al. Highly active platinum catalysts for nitrile and cyanohydrin hydration: catalyst design and ligand screening via high-throughput techniques. J. Am. Chem. Soc. 140, 17782-17789 (2018).

50. Frenking, G. \& Frohlich, N. The nature of the bonding in transition-metal compounds. Chem. Rev. 100, 717-774 (2000).

51. Clarke, M. L. et. al. The electron-poor phosphines $\mathrm{P}\left\{\mathrm{C}_{6} \mathrm{H}_{3}\left(\mathrm{CF}_{3}\right)_{2}-3,5\right\}_{3}$ and $\mathrm{P}$ $\left(\mathrm{C}_{6} \mathrm{~F}_{5}\right)_{3}$ do not mimic phosphites as ligands for hydroformylation. A comparison of the coordination chemistry of $\left.\mathrm{P}_{2} \mathrm{C}_{6} \mathrm{H}_{3}\left(\mathrm{CF}_{3}\right)_{2}-3,5\right\}_{3}$ and $\mathrm{P}$ $\left(\mathrm{C}_{6} \mathrm{~F}_{5}\right)_{3}$ and the unexpectedly low hydroformylation activity of their rhodium complexes. Dalton Trans. 2005, 1294-1300 (2005).

52. Rosenfeld, D. C., Shekhar, S., Takemiya, A., Utsunomiya, M. \& Hartwig, J. F. Hydroamination and hydroalkoxylation catalyzed by triflic acid. Parallels to reactions initiated with metal triflates. Org. Lett. 8, 4170-4182 (2006).

53. Taylor, J. G., Adrio, L. A. \& Hii, K. K. Hydroamination reactions by metal triflates: Brønsted acid vs. metal catalysis? Dalton Trans. 39, 1171-1175 (2010).

54. Dang, T. T., Boeck, F. \& Hintermann, L. Hidden Brøsted acid catalysis: pathways of accidental or deliberate generation of triflic acid from metal triflates. J. Org. Chem. 76, 9353-9361 (2011).

55. Chen, J., Goforth, S. K., Mckeown, B. A. \& Gunnoe, T. B. Brønsted acidcatalysed intramolecular hydroamination of unactivated alkenes: metal triflates as an in situ source of triflic acid. Dalton Trans. 46, 2884-2891 (2017).

56. Korenaga, T., Ko, A., Uotani, K., Tanaka, Y. \& Sakai, T. Synthesis and application of 2,6-bis(trifluoromethyl)-4-pyridyl phosphines: the most electron-poor aryl phosphanes with moderate bulkiness. Angew. Chem. Int. Ed. 50, 10703-10707 (2011).

57. Karshtedt, D., Bell, A. T. \& Tilley, T. D. Pt-Ag catalyst system for hydroarylations with unactivated arenes and olefins. Organometallics 23, 4169-4171 (2004).
58. Shigehisa, H. et al. Catalytic synthesis of saturated oxygen heterocycles by hydrofunctionalization of unactivated olefins: unprotected and protected strategies. J. Am. Chem. Soc. 138, 10597-10604 (2016).

59. Tsuji, N. et al. Activation of olefins via asymmetric Brønsted acid catalysis. Science 359, 1501-1505 (2018).

60. Ebisawa, K. et al. Catalyst- and silane-controlled enantioselective hydrofunctionalization of alkenes by cobalt-catalyzed hydrogen atom transfer and radical-polar crossover. J. Am. Chem. Soc. 142, 13481-13490 (2020)

61. Chen, D., Berhane, I. A. \& Chemler, S. R. Copper-catalyzed enantioselective hydroalkoxylation of alkenols for the synthesis of cyclic ethers. Org. Lett. 22, 7409-7414 (2020).

62. Hannedouche, J. \& Schulz, E. Asymmetric hydroamination: a survey of the most recent developments. Chem. Eur. J. 19, 4972-4985 (2013).

63. Reznichenko, A. L. Nawara-Hultzsch, A. J. \& Hultzsch, K. C. Asymmetric Hydroamination. Top Curr Chem 343, 191-260 (2014).

64. Gao, P. et al. Chiral NHC-iridium complexes and their performance in enantioselective intramolecular hydroamination and ring-opening amination reactions. Organometallics 39, 556-573 (2020).

65. Roos, C. B., Demaerel, J., Graff, D. E. \& Knowles, R. R. Enantioselective hydroamination of alkenes with sulfonamides enabled by proton-coupled electron transfer. J. Am. Chem. Soc. 142, 5974-5979 (2020).

66. Xi, Y., Ma, S. \& Hartwig, J. F. Catalytic asymmetric addition of an amine N-H bond across internal alkenes. Nature 588, 254-260 (2020).

67. Paull, D. H., Abraham, C. J., Scerba, M. T., Alden-Danforth, E. \& Lectka, T. Bifunctional asymmetric catalysis: cooperative lewis acid/base systems. Acc. Chem. Res. 41, 655-663 (2008).

\section{Acknowledgements}

We wish to thank Shenzhen Nobel Prize Scientists Laboratory Project, Shenzhen Science and Technology Program (Grant nos. KQTD20180411143514543 and K20215006), the National Natural Science Foundation of China (Grant no. K18211006), and the Natura Science Foundation of Guagndong Province (Grant no. K19213002) for financial support. Prof. Robbert H. Grubbs is acknowledged for helpful discussions and valuable suggestions.

\section{Author contributions}

Y.Z., X.X., H.S. and G.T. developed and conducted the reactions. X-Y.C. conducted the experiment for X-ray crystallography and did structure determination. C.X., B.C. and X.X. designed and directed the investigations. C.X. and B.C. wrote the paper.

\section{Competing interests}

The authors declare no competing interests.

\section{Additional information}

Supplementary information The online version contains supplementary material available at https://doi.org/10.1038/s41467-021-22287-w.

Correspondence and requests for materials should be addressed to X.X., B.C. or C.X.

Peer review information Nature Communications thanks Piet van Leeuwen, Chao Chen and the other anonymous reviewers for their contribution to the peer review of this work

Reprints and permission information is available at http://www.nature.com/reprints

Publisher's note Springer Nature remains neutral with regard to jurisdictional claims in published maps and institutional affiliations.

pen Access This article is licensed under a Creative Commons Attribution 4.0 International License, which permits use, sharing, adaptation, distribution and reproduction in any medium or format, as long as you give appropriate credit to the original author(s) and the source, provide a link to the Creative Commons license, and indicate if changes were made. The images or other third party material in this article are included in the article's Creative Commons license, unless indicated otherwise in a credit line to the material. If material is not included in the article's Creative Commons license and your intended use is not permitted by statutory regulation or exceeds the permitted use, you will need to obtain permission directly from the copyright holder. To view a copy of this license, visit http://creativecommons.org/ licenses/by/4.0/

(c) The Author(s) 2021 